\title{
Neogene Paleoclimatic Changes in Response to Tectonism in the Himalayan Gyirong Basin, China
}

\author{
Xu Yadong* (徐亚东), Zhang Kexin (张克信) \\ Key Laboratory of Biogeology and Environmental Geology of Ministry of Education, China University of \\ Geosciences, Wuhan 430074, China; Faulty of Earth Sciences, China University of Geosciences, \\ Wuhan 430074, China \\ Wang Guocan (王国灿) \\ Faulty of Earth Sciences, China University of Geosciences, Wuhan 430074, China; State Key Laboratory of \\ Geological Processes and Mineral Resources, China University of Geosciences, Wuhan 430074, China \\ Jiang Shangsong (江尚松), Xiang Shuyuan (向树元) \\ Faulty of Earth Sciences, China University of Geosciences, Wuhan 430074, China \\ Chen Fenning (陈奋宁) \\ $X i$ 'an Institute of Geology and Mineral Resources, Xi'an 710054, China; Faulty of Earth Sciences, China \\ University of Geosciences, Wuhan 430074, China
}

\section{Carina Hoorn}

Institute for Biodiversity and Ecosystem Dynamics, University of Amsterdam, Kruislaan 318, 1098 SM Amsterdam, The Netherlands

Guillaume Dupont-Nivet

Paleomagnetic Laboratory, Utrecht University, Budapestlaan 17, 3584 CD Utrecht, The Netherlands

The Gyirong basin is one of the east-westward extensional basins distributed among the high Himalayas, where a suit of alluvial- and fluvial-lacustrine deposits (Danzengzhukang Formation and Woma Formation), and a Hipparion fauna along with molluscs, ostracods and pollen were found in Neogene sequence. Results of zircon and apatite fission track thermochronology and palaeo-magnetostratigraphic results in this basin bracket the age interval of the section most reasonably between 10 and $1.7 \mathrm{Ma}$.

Based on lithology, paleo-current of water mass

This study was supported by the China Geological Survey (No. 1212010610103).

*Corresponding author: yuren36@gmail.com; y.xu@uva.nl

(C) China University of Geosciences and Springer-Verlag Berlin Heidelberg 2010

Manuscript received December 22, 2009.

Manuscript accepted February 20, 2010. and provenance analysis, accompanied by investigation data of palynology, ostracodas and clay mineralogy, 3 phases of paleoenvironmental changes are identified, and they include (1) an SE-E paleo-current of alluvial-fan lithofacies (Danzengzhukang Formation, 10-7.4 Ma), with occurrence of warm and humid coniferous- and broad-leaved mixed forests (1 600 to $3000 \mathrm{~m}$ ); (2) an SWW paleo-current of the fluviallacustrine lithofacies (Lower Woma Formation, 7.4$3.3 \mathrm{Ma}$ ), shown by the appearance of cold and arid deciduous coniferous-leaved forests ( 2000 to 4000 m); (3) an SW paleo-current of the lacustrine-fan delta lithofacies (Upper Woma Formation, 3.3-1.7 Ma), going into cool and humid deciduous coniferous- and broad-leaved mixed forests during 2.6-1.7 Ma (2 500 to $4600 \mathrm{~m})$. We deduce three vivid uplift events are observed at 7.4, 3.3 and $2.6 \mathrm{Ma}$, respectively. The overall cooling trend since $7.4 \mathrm{Ma}$ is an interplay between tectonism and climatic changes. 